\title{
Analytical Study on Dynamic Response of Deep Foundation Pit Support Structure under the Action of Subway Train Vibration Load: A Case Study of Deep Foundation Pit of the New Museum Near Metro Line 2 in Chengdu, China
}

\author{
Zhu Dapeng, ${ }^{1}$ Qin Liangkai, ${ }^{2}$ and Lin Yundian ${ }^{3}$ \\ ${ }^{1}$ School of Geoscience and Technology, Southwest Petroleum University, Chengdu 610500, China \\ ${ }^{2}$ School of Civil Engineering and Architecture, Southwest Petroleum University, Chengdu 610500, China \\ ${ }^{3}$ Hanlin (Fujian) Investigation and Design Co., Ltd., Fuzhou 350000, China \\ Correspondence should be addressed to Qin Liangkai; 973026959@qq.com
}

Received 9 April 2015; Revised 25 July 2015; Accepted 4 August 2015

Academic Editor: Tony Murmu

Copyright @ 2015 Zhu Dapeng et al. This is an open access article distributed under the Creative Commons Attribution License, which permits unrestricted use, distribution, and reproduction in any medium, provided the original work is properly cited.

Presently, foundation pit support structures are generally regarded as the temporary structures and the impact of vibration loads is often overlooked. As opposed to static and seismic loads, the vibration loads of subway trains are a type of cyclic load with a relatively long duration of action and a definite cycle; it is of great importance for the design of foundation pit support structures to correctly evaluate the impact of subway train vibrations on deep foundation pit and support works. In this paper, a dynamic threedimensional numerical model is built that considers the vibration load of subway trains on the basis of the static numerical model for deep foundation pit support structures and simplified train loads to study the impact of train vibrations on deep foundation pit and permanent support structures. Studies have shown that the dynamic response of surface displacement mainly occurs in the early period of dynamic load, the vibration load of subway trains has little impact on ground subsidence, the support pile structure is in an elastic state during dynamic response under the action of subway train vibrations, and the action of train vibration loads is inimical to the safety of foundation pit support structures and should be closely studied.

\section{Introduction}

Presently, foundation pit support structures are generally regarded as temporary structures and the impact of vibration loads is often overlooked, which does not fit in with the actual stress situation of foundation pits. The existing static equilibrium of foundation pits is upset by the effect of ambient vibration and changes from a stable state to unstable state. Once instability is caused, it will definitely bring great damage to people's lives and property. For example, road collapse suddenly occurred in the foundation pit construction site of Xianghu Station of Metro Line 1, Fengqing avenue, Xiaoshan district, Hangzhou, on November 15, 2008. One of the causes for this accident was that Fengqing avenue, where the foundation pit lies, had been used as a trunk road and the lateral displacement of the retaining diaphragm west of the foundation pit was increased by the loads of running vehicles. On March 19, 2009, slope failure occurred in the foundation pit of Jiahao plaza, Xining, and the vibration from construction was an inducing factor for the accident. In 2010, the planning and construction of rail transit was carried out in nearly 30 cities and regions of China, involving up to more than 110 lines. Subway construction entered a period of huge growth. In Chengdu, for example, ten subway lines were planned with a total length of $348.2 \mathrm{~km}$. Line 1 and Line 2 were put into operation in October 2010 and September 2012, respectively. As an important part of urban underground space and rail transit, subway lines usually go through areas with dense population and buildings. The impact of the vibrations of running trains on the surrounding environment has 
attracted increasing attention from academic and engineer circles [1-3].

A foundation pit is usually in a complex environment. The impact of the vibration of road vehicles, neighboring subway trains, earthquakes, and construction blasting in the environment must be considered [4-8]. Scholars at home and abroad have conducted a lot of research on the deformation and stability of foundation pits under static loads and achieved fruitful results. However, little research has been conducted on foundation pit deformation and instability caused by ambient vibration (i.e., dynamic loads). In recent years, research on the impact of rail excitation loading on neighboring subway foundation pit works has become a hot topic as urban rail transit has further developed. For example, Hall [9] (2003) obtained the basic laws of surface vibrations under train loads through finite element numerical model analysis. Bi and Zhou [10] (2004) analyzed the dynamic response of deep foundation pit structure in new parallel interchange stations under rail excitation loading. $\mathrm{Ma}$ et al. [11] established a corresponding three-dimensional numerical model with FLAC ${ }^{3 \mathrm{D}}$ and analyzed the dynamic response of deep foundation pits and support structures under train load and proposed that train speed has a major impact on the dynamic response of the deep foundation pit support structure, providing a reference for the design of such structures. Andersen and Jones [12] (2006) compared 2D and 3D models in terms of their correlation and difference with coupled boundary conditions and the finite element method (FEM). Hu and Jian [13] (2010), after dynamic testing and spectral analysis of sites influenced by train excitation, analyzed the inherent characteristic of fully grouted rock bolts and derived the formulas for the natural frequency and vibration of the bolts. The studies revealed that the first vertical frequency of the bolts, the predominant frequency of the site, and the dominant frequency of the train are in different frequency ranges and train excitation does not result in resonance of the bolts, which provides a reference for further understanding of the applicability of bolt support structure in a train vibration environment.

Thus, previous vibration studies focused on the dynamic response of shallow foundation pits and subway tunnels under ambient vibration conditions. However, there are no references on the impact of vibration on deep foundation pits and permanent support structures. Therefore, the study of the internal force and deformation of deep foundation pits and permanent support structures under train vibration loading in this paper is of great importance.

In this paper, the New Chengdu Museum deep foundation pit in China is taken as the object of study and the established numerical model [14]; the authors will determine the constitutive rock and soil model and structural unit type and establish a geometric model for deep foundation pits and then calculate the pit excavation static values with FLAC ${ }^{3 \mathrm{D}}$, take the foundation pit model after excavation and support completion as the basic model of dynamic analysis, and then conduct dynamic calculations by considering the effect of rail excitation loading, in order to study the dynamic response laws in deep foundation pits under subway train loading.

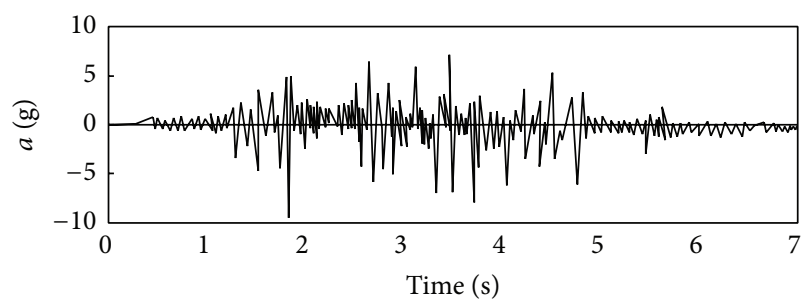

FIGURE 1: Measured rail vertical acceleration time history curve.

\section{Train Vibration Load Simulation}

This paper mainly studies the response laws of soil and support structure in a deep foundation pit under subway train vibration loading, so it is particularly important to determine the train vibration load. Vibration load is the periodic excitation vibration caused by the impact of running trains on the rails, wheel vibration, and irregularities of the rails caused by long-term operation as well as the eccentricity of the wheels. In this paper, spectral analysis is conducted on the basis of measured data from the site and then the vibration load of the train is derived; finally the value of the vibration load is calculated.

2.1. Spectral Analysis of Rail Vibration Acceleration. The expression of the oscillogram of actually measured rail acceleration (as shown in Figure 1 [15]) is unknown. It is generally considered to be a stationary Gaussian process featuring zero mean. Thus the actual measured rail acceleration oscillogram can be decomposed into a series of harmonic waves with different frequencies, namely, many different sine and cosine wave diagrams. It can be expressed with a Fourier series as follows [16-18]:

$$
x(t)=\sum_{k=0}^{\infty}\left(A_{k} \cos k \omega t+B_{k} \sin k \omega t\right)
$$

where

$$
\begin{aligned}
A_{k} & =\frac{2}{T} \int_{0}^{T} x(t) \cos k \omega t d t \\
B_{k} & =\frac{2}{T} \int_{0}^{T} x(t) \sin k \omega t d t
\end{aligned}
$$

$t$ is the recorded duration or truncated duration; $k$ is the number of steps; $\omega$ is the circular frequency.

The acceleration oscillogram is divided into $N$ points and the Fourier transformation is conducted on this basis; the corresponding Fourier series and circular frequency are obtained. The Fourier series direct transformation is

$$
C_{k}=\frac{1}{N} \sum_{j=0}^{N-1} x_{j} \exp \left(-i \frac{2 \pi k j}{N}\right) .
$$


The result of formula (3) is symmetrical for the point $k=N / 2$. For the purpose of simplification, only half is taken; namely,

$$
\begin{aligned}
C_{k} & =\frac{1}{N} \sum_{j=0}^{N-1} x_{j} \exp \left(-i \frac{2 \pi k j}{N}\right) \\
& =\frac{1}{N} \sum_{j=0}^{N-1} x_{j}\left(\cos \frac{2 \pi k j}{N}-i \sin \frac{2 \pi k j}{N}\right) \\
& =\frac{1}{2}\left(A_{k}-i B_{k}\right) .
\end{aligned}
$$

In formula (4),

$$
\begin{aligned}
A_{k} & =\frac{2}{N} \sum_{j=0}^{N-1} x_{j} \cos \frac{2 \pi k j}{N} ; \quad k=0,1,2, \ldots, \frac{N}{2}-1 \\
B_{k} & =\frac{2}{N} \sum_{j=0}^{N-1} x_{j} \sin \frac{2 \pi k j}{N} ; \quad k=0,1,2, \ldots, \frac{N}{2}-1 .
\end{aligned}
$$

So the Fourier coefficients are as follows:

$$
\begin{aligned}
& A_{k}=C_{k}+\bar{C}_{k}, \\
& B_{k}=C_{k}-\bar{C}_{k},
\end{aligned}
$$

where $\bar{C}_{k}$ is the conjugate complex number of $C_{k}$.

The deterministic expression of the rail vibration oscillogram is

$$
x(t)=\sum_{k=0}^{N / 2-1}\left(A_{k} \cos k \omega t+B_{k} \sin k \omega t\right),
$$

where $\omega=2 \pi / N \Delta t$ is the circular frequency and $\Delta t$ is the sampling interval.

In the above formulae, $N$ refers to the number of data collected. In this analysis, FFT is used for Fourier transformation to obtain $C_{k}$; the values of $A_{k}$ and $B_{k}$ are found according to formula (6). Thus the simulation formula (7) of rail vibration acceleration is determined.

2.2. Train Vibration Load Calculation. Before the simulation of train vibration load and when the train model is simplified, the following hypothesis needs to be made [19]:

(1) A running train produces much greater vertical excitation than horizontal excitation on the railway roadbed beneath the rail, so the horizontal excitation can be ignored.

(2) Regarding the impact on bounce between the wheel and rail and the sway and nodding of the train in motion, suppose the weight of the train can be evenly distributed on the wheels; we can take only one wheel system as the computation model. The simplified model of simulated interaction between the rail and wheel system is shown in Figure 2.

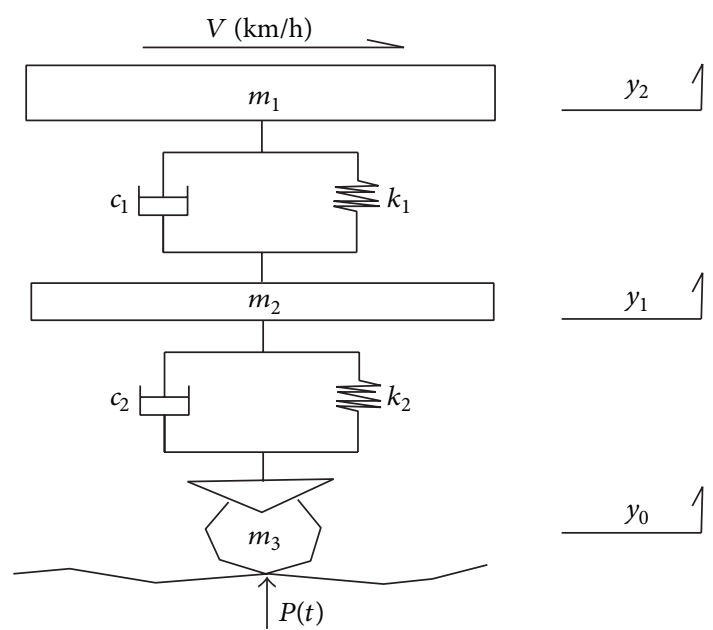

FIGURE 2: Simplified model of wheel and rail.

In Figure $2, m_{i}, k_{i}$, and $c_{i}$, respectively, denote mass, spring stiffness, and damping coefficients. $y_{0}, y_{1}$, and $y_{2}$ are reference coordinate systems, respectively, corresponding to the static equilibrium position of each mass. The locomotive engines of Chengdu Metro Line 2 were manufactured by CSR Qingdao Sifang Co., Ltd. The parameters of the simplified wheel and rail model according to locomotive engine and train model are as follows: $m_{1}=642.202 \mathrm{~kg} \cdot \mathrm{s}^{2} / \mathrm{m}, c_{1}=$ $70000 \mathrm{~kg} \cdot \mathrm{s} / \mathrm{m}, k_{1}=172000 \mathrm{~kg} / \mathrm{m}, m_{2}=198.776 \mathrm{~kg} \cdot \mathrm{s}^{2} / \mathrm{m}, c_{2}=$ $100000 \mathrm{~kg} \cdot \mathrm{s} / \mathrm{m}, k_{2}=107000 \mathrm{~kg} / \mathrm{m}$, and $m_{3}=326.197 \mathrm{~kg} \cdot \mathrm{s}^{2} /$ $\mathrm{m}$.

The dynamic balance equation of the wheel system is established as follows:

$$
\begin{aligned}
& m_{1} \ddot{y}_{2}+k_{1}\left(y_{2}-y_{1}\right)+c_{1}\left(\dot{y}_{2}-\dot{y}_{1}\right)=0 \\
& m_{2} \ddot{y}_{1}+k_{2}\left(y_{1}-y_{0}\right)+c_{2}\left(\dot{y}_{1}-\dot{y}_{0}\right)+k_{1}\left(y_{1}-y_{2}\right) \\
& \quad+c_{1}\left(\dot{y}_{1}-\dot{y}_{2}\right)=0,
\end{aligned}
$$

where $\dot{y}=d y / d t$ and $\ddot{y}=d^{2} y / d t^{2}$.

If the bounce effect between rail and wheel is ignored, the vertical acceleration $\ddot{y}$ of the wheel system is equal to the rail bottom vibration acceleration. Then,

$$
\ddot{y}_{0}=x(t)=\sum_{k=0}^{N / 2-1}\left(A_{n} \cos n \omega t+B_{n} \sin n \omega t\right) .
$$

Equation (9) is substituted into (8) and (8) is solved according to the initial conditions.

According to vertical dynamic equilibrium conditions, the wheel-rail interaction force $P(t)$ is obtained as follows:

$$
P(t)=m_{1} \ddot{y}_{2}+m_{2} \ddot{y}_{1}+m_{3} \ddot{y}_{0}+\left(m_{1}+m_{2}+m_{3}\right) g .
$$

Equation (8) is substituted into (10) and we obtain

$$
P(t)=11450+\sum_{k=0}^{N / 2-1}\left(W_{n} \cos n \omega t+Z_{n} \sin n \omega t\right),
$$


where

$$
\begin{aligned}
W_{n} & =1167.1764 A_{n}-840.9786 S_{n}-642.2018 E_{n} n^{2} \omega^{2} \\
Z_{n} & =1167.1764 B_{n}-840.9786 T_{n}-642.2018 F_{n} n^{2} \omega^{2} \\
S_{n} & =A_{n}+A_{11} E_{n}+B_{11} F_{n} n \omega-E_{n} n^{2} \omega^{2} \\
T_{n} & =B_{n}+A_{11} F_{n}-B_{11} E_{n} n \omega-F_{n} n^{2} \omega^{2} \\
E_{n} & =\frac{Q_{n} G_{n}-P_{n} H_{n}}{P_{n}^{2}+Q_{n}^{2}} \\
F_{n} & =\frac{Q_{n} H_{n}-P_{n} G_{n}}{P_{n}^{2}+Q_{n}^{2}} \\
P_{n} & =P_{3} n \omega-P_{1} n^{3} \omega^{3} \\
Q_{n} & =P_{4}-P_{2} n^{2} \omega^{2}+n^{4} \omega \\
G_{n} & =-A_{22} A_{n}-B_{22} B_{n} n \omega \\
H_{n} & =-A_{22} B_{n}-B_{22} A_{n} n \omega \\
P_{1} & =964.23 \\
P_{2} & =56506.81 \\
P_{3} & =193412.44 \\
P_{4} & =144170.21 \\
A_{22} & =538.29 \\
B_{22} & =503.08 \\
A_{11} & =267.83 \\
B_{11} & =109.0 . \\
&
\end{aligned}
$$

Assuming that $P(t)$ is transmitted via rail to the railway roadbed and becomes line load $F(t)$ longitudinally distributed evenly along the rail, the deterministic expression of the vertical vibration load of the train is [17-19]

$$
F(t)=\frac{P(t)}{L} \times n_{1},
$$

where $n_{1}$ is the number of wheel pairs of each carriage, $n_{1}=4$, and $L$ is the length of each carriage, $L=13.44 \mathrm{~m}$.

In this paper, the object of analysis is the deep foundation pit works of the New Chengdu Museum; east of the museum is the Tianfu Square Station of the Chengdu Metro. The train speed varies from 10 to $30 \mathrm{~km}$ when entering and leaving the station. According to a large amount of actual measurements of subway train vibrations made by domestic and foreign scholars, the ambient vibration induced by a running train increases with the increase of train speed. The train dynamic load diagram (Figure 3) is obtained step by step with the above formula on the basis of the actually measured rail base acceleration time history when a train is running at the speed of $70 \mathrm{~km} / \mathrm{h}$. According to the provisions, $70 \mathrm{~km} / \mathrm{h}$ is currently the highest speed of urban subway trains in China, so the result of train vibration load calculation on the basis of this speed can be considered the most unfavorable load.

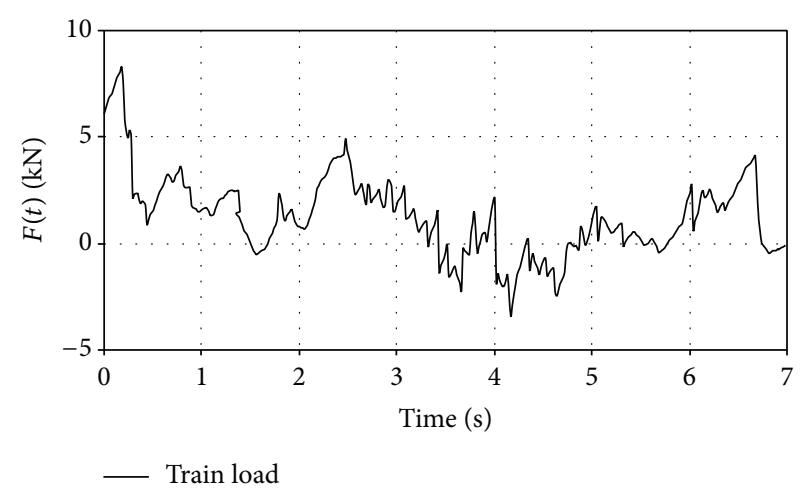

FIGURE 3: Subway train vibration load diagram.

\section{Foundation Pit 3D Dynamic Model and Parameter Determination}

3.1. Project Overview. The deep foundation pit of the New Chengdu Museum is located west of Tianfu square, adjacent to Renmin middle road on the east and Xiyu street on the south, Xiaohe street on the west, and Sudu road on the north. The foundation pit is next to the Tianfu square transit hub of Chengdu metro. The foundation pit excavation line has a circumference of $410 \mathrm{~m}$ and an excavation depth of $25.4 \mathrm{~m}$, with areas $26.6 \mathrm{~m}$ deep. A base isolation system has been adopted for the structure. The site elevation \pm 0.00 is equivalent to an absolute elevation of $504.50 \mathrm{~m}$. The absolute elevation of the surrounding environment is about $502.50 \mathrm{~m}$ $(-2.20 \mathrm{~m})$; the pit bottom elevation is $-25.40 \mathrm{~m}(-26.60 \mathrm{~m}$ in some areas).

The floor plan of the foundation pit is shown in Figure 4. A pile-anchor structure has been adopted for the foundation pit support of this project. The pile top elevation is designed to be $-4.00 \mathrm{~m}$. A double pile and anchor rod supporting scheme has been adopted for the north slope support system. A single pile and anchor cable supporting system has been adopted for slope support in other areas. According to the site and ground conditions, as well as the requirements of the construction unit, a rotary drilling rig was used for mechanical drilling of the piles. A double supporting wall and piles surround the isolation ditch in combined action to form a permanent building enclosure.

3.2. Numerical Model Establishment and Calculation Parameters Selection. The deep foundation pit works of the Chengdu Museum are taken as an example to establish a dynamic numerical model for deep foundation pits. First, the pit excavation static values calculations and then the dynamic calculations are conducted. Therefore, after excavation and support structure completion in static value calculation, the pit model can be used as a basic model for dynamic analysis, as shown in Figures 5-7. The stratum media from top to bottom include six layers, namely, miscellaneous fill, slightly compact gravel, moderately compact pebble bed, compact pebble bed, strongly weathered mudstone, and moderately weathered mudstone. The range is $500 \mathrm{~m}$ in the $X$ direction, $300 \mathrm{~m}$ in the $Z$ direction, and $-75.4 \mathrm{~m}$ deep in the $Y$ direction. 


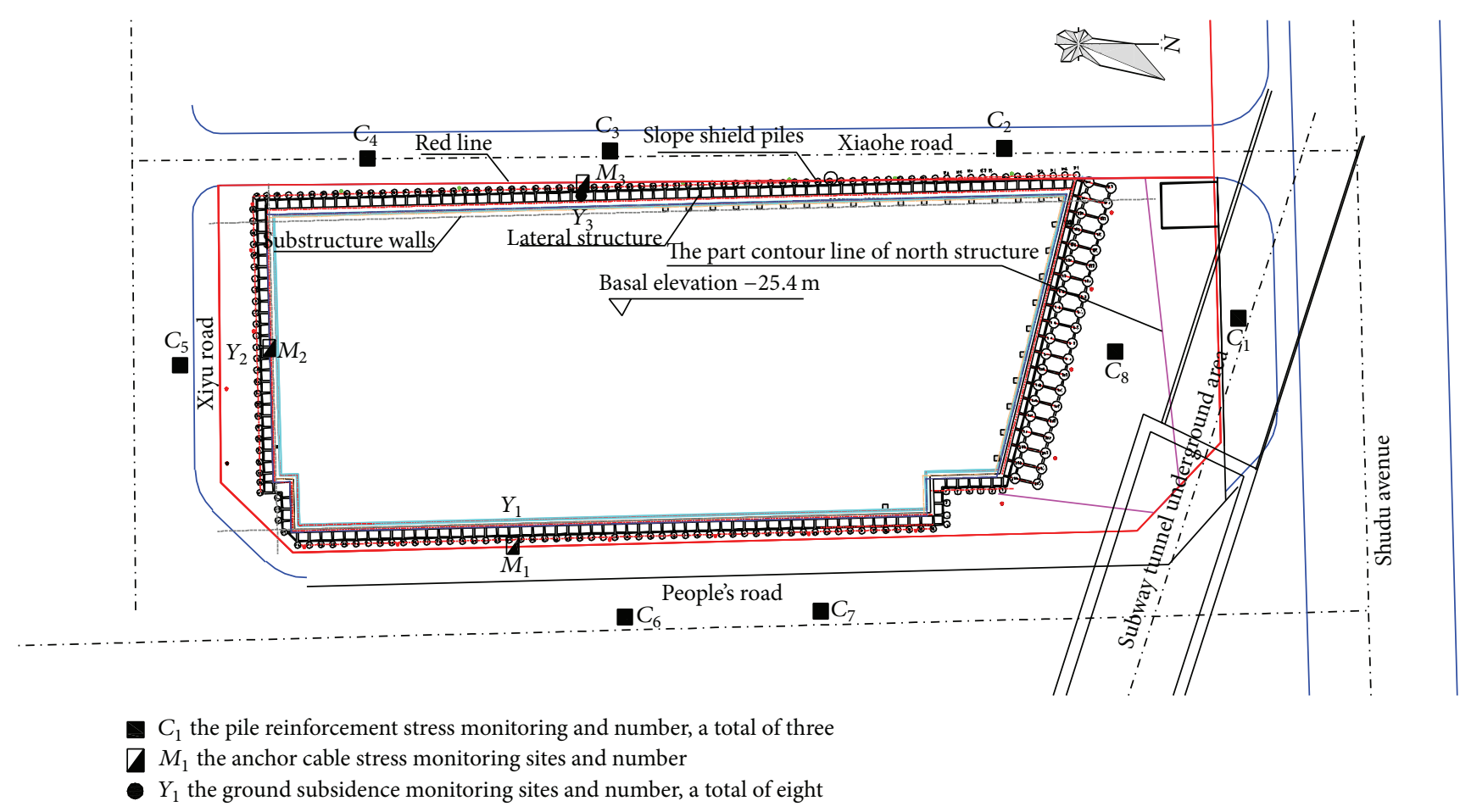

FIGURE 4: Floor plan of deep foundation pit of Chengdu Museum.

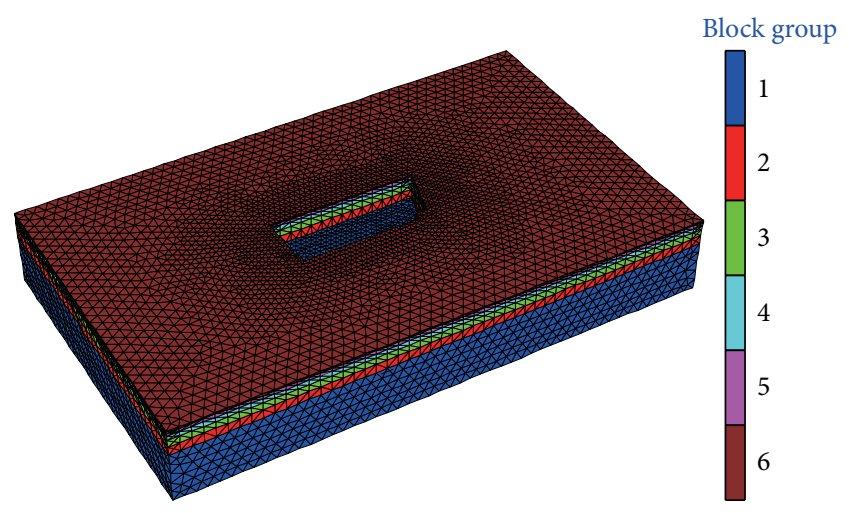

FIGURE 5: Numerical model after static calculation.

In accordance with Geotechnical Investigation Report of the New Chengdu Museum, geotechnical material parameters of the deep foundation pit of new Chengdu Museum are listed in Table 1.

In a numerical simulation of deep foundation pit excavation and support structure construction, the parameters for the support piles, top beam, and anchor cable of the support structure need to be set. In this paper, support structure parameters are provided according to the Structural Design of Deep Foundation Pit Support Engineering for Chengdu Museum, as shown in Tables 2-4.

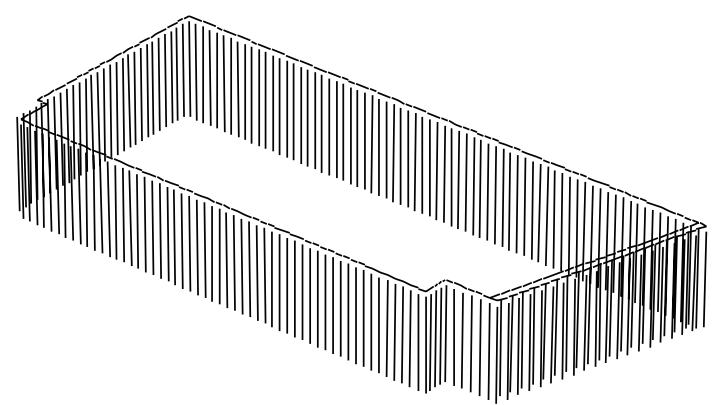

FIgURE 6: Support pile and top beam structure model.

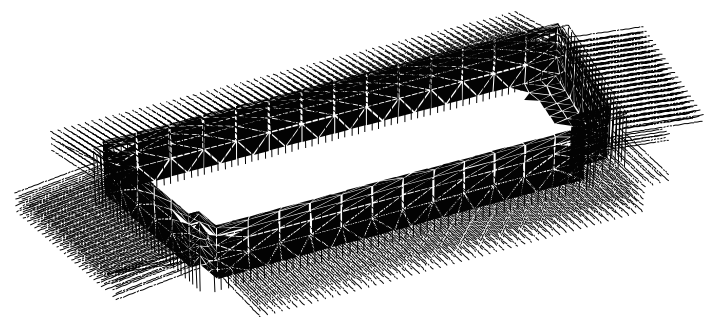

FIGURE 7: Lining work and prestressed cable structure model.

\section{Analysis of Results}

4.1. Foundation Soil Settlement Analysis. In a dynamic analysis numerical model, the four monitoring points of DC3, DC5, DC7, and DC8 are established surrounding the deep 
TABLE 1: Geomaterial parameters table.

\begin{tabular}{|c|c|c|c|c|c|c|c|c|}
\hline Material & Stratum & $\begin{array}{c}\text { Density } \rho \\
\left(\mathrm{kg} / \mathrm{m}^{3}\right)\end{array}$ & $\begin{array}{l}\text { Deformation } \\
\text { modulus } E_{0} \\
(\mathrm{Mpa})\end{array}$ & $\begin{array}{l}\text { Poisson's } \\
\text { ratio } \mu\end{array}$ & $\begin{array}{c}\text { Friction } \\
\text { angle } \varphi\left({ }^{\circ}\right)\end{array}$ & $\begin{array}{l}\text { Cohesion } \\
c(\mathrm{MPa})\end{array}$ & $\begin{array}{c}\text { Tensile } \\
\text { strength } \\
\sigma_{t}(\mathrm{MPa})\end{array}$ & $\begin{array}{c}\text { Thickness } \\
\text { (m) }\end{array}$ \\
\hline 1 & Miscellaneous fill & 1.75 & 30 & 0.35 & 9.0 & 0.01 & 0.00 & 1.4 \\
\hline 2 & Slightly compact gravel & 2.10 & 50 & 0.28 & 38.0 & 0.00 & 0.00 & 3.5 \\
\hline 3 & Moderately compact gravel & 2.15 & 60 & 0.25 & 43.0 & 0.00 & 0.00 & 4.5 \\
\hline 4 & Compact gravel & 2.20 & 70 & 0.22 & 45.0 & 0.00 & 0.00 & 7.0 \\
\hline 5 & Strong weathering & 2.25 & 200 & 0.28 & 30 & 0.08 & 0.01 & 9.0 \\
\hline 6 & $\begin{array}{l}\text { Moderately weathered } \\
\text { mudstone }\end{array}$ & 2.30 & 500 & 0.30 & 35.0 & 0.30 & 0.10 & 50 \\
\hline
\end{tabular}

TABLE 2: Supporting pile body design parameters.

\begin{tabular}{lcccccc}
\hline Location & $\begin{array}{c}\text { Diameter } \\
(\mathrm{m})\end{array}$ & $\begin{array}{c}\text { Length } \\
(\mathrm{m})\end{array}$ & $\begin{array}{c}\text { Embedded } \\
\text { depth }(\mathrm{m})\end{array}$ & $\begin{array}{c}\text { Spacing } \\
(\mathrm{m})\end{array}$ & $\begin{array}{c}\text { Top beam } \\
\text { section }(\mathrm{m} \times \mathrm{m})\end{array}$ & $\begin{array}{c}\text { Clear distance between } \\
\text { front and rear row piles }(\mathrm{m})\end{array}$ \\
\hline North & 2.0 & 26.5 & 5.6 & 2.8 & $2.0 \times 1.0$ & 2.0 \\
East & 1.2 & 26.5 & 5.1 & 2.0 & $1.2 \times 0.8$ & - \\
South & 1.2 & 26.5 & 5.1 & 2.0 & $1.2 \times 0.8$ & - \\
West & 1.2 & 26.5 & 5.1 & 2.0 & $1.2 \times 0.8$ & - \\
\hline
\end{tabular}

TABLE 3: Design parameters of anchor cables of northern support pile system.

\begin{tabular}{lccccc}
\hline Location & Anchor cable Location & Dip & Anchor cable length & $\begin{array}{c}\text { Anchoring } \\
\text { segment length }\end{array}$ & $\begin{array}{c}\text { Anchoring } \\
\text { location }\end{array}$ \\
\hline 1st anchor cable & $-10.0 \mathrm{~m}$ & $5^{\circ} \sim 10^{\circ}$ & $25.0 \mathrm{~m}$ & $17.0 \mathrm{~m}$ & $\begin{array}{c}\text { One pile with } \\
\text { one anchor }\end{array}$ \\
2nd anchor cable & $-13.0 \mathrm{~m}$ & $5^{\circ} \sim 10^{\circ}$ & $25.0 \mathrm{~m}$ & $17.0 \mathrm{~m}$ & $\begin{array}{c}\text { One pile with strands } \\
\text { one anchor }\end{array}$ \\
\hline
\end{tabular}

TABLE 4: Design parameters of anchor cables of eastern, southern, and western support pile systems.

\begin{tabular}{lccccc}
\hline Location & $\begin{array}{c}\text { Anchor cable } \\
\text { location }\end{array}$ & Dip & $\begin{array}{c}\text { Anchor cable } \\
\text { length }\end{array}$ & $\begin{array}{c}\text { Anchoring } \\
\text { segment length }\end{array}$ & Anchoring location \\
\hline 1st anchor cable & $-9.0 \mathrm{~m}$ & $10^{\circ} \sim 15^{\circ}$ & $25.0 \mathrm{~m}$ & $17.0 \mathrm{~m}$ & One pile with one anchor \\
2nd anchor cable & $-12.0 \mathrm{~m}$ & $10^{\circ} \sim 15^{\circ}$ & $25.0 \mathrm{~m}$ & $17.0 \mathrm{~m}$ & One pile with one anchor strands \\
3rd anchor cable & $-15.0 \mathrm{~m}$ & $10^{\circ} \sim 15^{\circ}$ & $25.0 \mathrm{~m}$ & $17.0 \mathrm{~m}$ & One pile with one anchor strands \\
4th anchor cable & $-18.0 \mathrm{~m}$ & $10^{\circ} \sim 15^{\circ}$ & $25.0 \mathrm{~m}$ & $17.0 \mathrm{~m}$ & One pile with one anchor $\quad 7$ steel strands \\
\hline
\end{tabular}

foundation pit (refer to Figure 4) in order to analyze surface subsidence surrounding the pit under the effect of subway train vibration loads. Figure 8 is the time history diagram of surface subsidence surrounding the foundation pit. Since the displacement subsidence obtained from static calculations has been cleared before dynamic calculation, that is, the initial values are 0 , the displacement and subsidence in Figure 8 are mainly caused by subway train vibration loads. As can be seen from Figure 8, a sudden subsidence occurs within the first second at the monitoring site DC3 in the middle western area of the foundation pit, with a maximum subsidence of $-2.27 \mathrm{~mm}$. And in a subsequent period of subway train vibration loads, the subsidence at DC3 was stable. Similar to DC3, subsidence at DC5, DC7, and DC8 mainly occurred within the first seconds, and then increase and decrease of displacement occurred alternatively. In the later period (from $1 s-7 s$ ), displacement subsidence at the three points remained stable. The final displacement subsidence values at DC3, DC5, DC7, and DC8 were, respectively, $-2.26 \mathrm{~mm},-0.39 \mathrm{~mm}$, $-0.87 \mathrm{~mm}$, and $-0.77 \mathrm{~mm}$.

As can be seen from a comparative analysis of the four subsidence curves in Figure 8, in the sandy cobble stratum media of Chengdu Plain where the site lies, the dynamic response of surface displacement mainly occurs in the early period of dynamic loading; train vibration is damped fast; surface displacement remains stable in the later period as the energy of surface displacement decays due to the damping of stratum soil; the vibration load of subway trains has little impact on ground subsidence, with a maximum subsidence of $-2.26 \mathrm{~mm}$, no more than the allowable value of $0.15 H \%$ ( $H$ is 


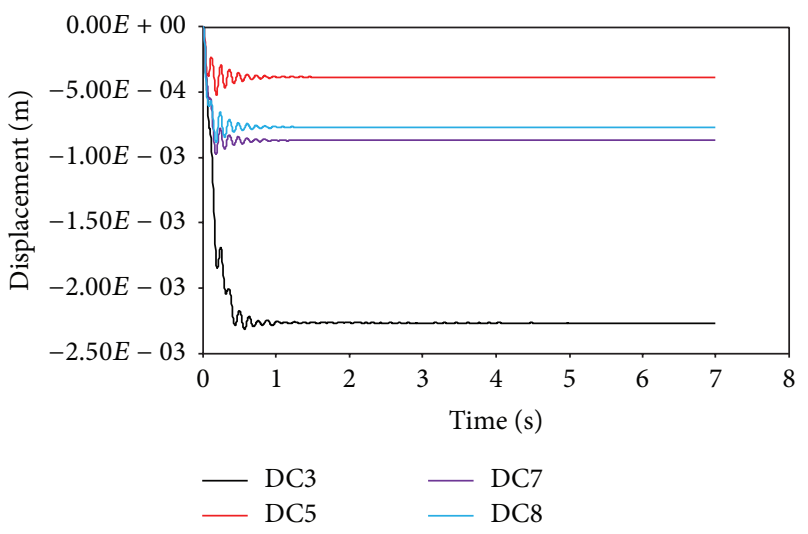

FIgURE 8: Time history diagram of surface displacement at the monitoring points surrounding the foundation pit. West monitoring site DC3 (black), south monitoring site DC5 (red), east monitoring site DC7 (purple), and north monitoring site DC8 (blue).

the pit excavation depth). Among the final surface subsidence values obtained from dynamic analysis and calculation, the final subsidence at the monitoring site DC5 in the middle southern area of the pit and farthest from Metro Line 2 was the smallest; the final subsidence at DC3 in the west of the pit was the largest, followed by that of DC8 in the north. It can be concluded on the basis of the above results that surface subsidence caused by the vibration loads of subway trains is smaller than the rated value and basically has no negative effect; surface vibration response becomes weaker and weaker with the increase of distance from the source of train vibrations; the two rows of support piles at DC8 north of the pit and nearest to the vibration source have effectively reduced the surface vibration response.

Taking Nanjing Metro Line 2 as an example, Yang and Cao [20] analyzed influence of train dynamic load on surface soil mass, structure of foundation pit support, and metro tunnel. Compared to the research result by Yang and Cao [20], the papers with numerical difference lead to a similar conclusion that the train dynamic load has a small influence on the stress and distortion of the surface subsidence and the foundation pit support structure and within the safety range. Furthermore, the study provides a change profile of displacement subsidence over time and gives a clear picture of dynamic response.

4.2. Stress Analysis of the Foundation Pit. Figures 9 and 10 are the $X$ and the $Y$ direction principal stress, respectively. As can be seen from Figure 9, it is known that the north and south side of the foundation pit appears in the $X$ direction of tensile stress. The biggest tensile stress is $100.46 \mathrm{kPa}$, and it is located at the north side, which is nearest to the origin of the train vibration load. Compared with the static calculation, the biggest tensile stress increases $17.26 \mathrm{kPa}$, and its amplification is $20.7 \%$. Figure 10 shows that the north side appears in $Y$ direction of tensile stress which is different from the static process. Thus, the vibration of subway trains has significant impact on the Earth pressure behind the pile, and the closer the origin of vibration, the more intense the dynamic response. Therefore, when we design the supporting structure near subway tunnel, the influence of the train vibration to the stability of the foundation pit should be considered completely, and the deformation monitoring near the origin of vibration should be intensified during the process of construction.

In the dynamic analysis, the soil body is usually regarded as continuous medium. In fact, soil body consists of the framework (soil particles) and the fluid inside the pore, once the cementing force between soil particles becomes smaller, the framework of soil body is more instable. The vibration load of subway trains is weaker than that of explosion or earthquake load, the energy loss is also smaller because of the relative motion between particles, the soil raises the compressive stress with a little tensile stress, and it keeps the elastic-viscous and is not destroyed.

4.3. Dynamic Response of Support Piles. Figure 11 shows the time history curves of support pile bending moments at the monitoring points (refer to Figure 4) under the train vibration loads. As can be seen from Figure 13, the pile bending moment at the monitoring site DY1 displayed a significant decreasing trend within the first $1.5 \mathrm{~s}$. From $1.5 \mathrm{~s}$ to $3 \mathrm{~s}$, the bending moment gradually rose, with a change of about $270 \mathrm{kN} \cdot \mathrm{m}$. After $3 \mathrm{~s}$, the bending moment at DY1 tended to be stable after a transient decrease and increase, with a final value of $2790 \mathrm{kN} \cdot \mathrm{m}$. Thus, it can be concluded that the dynamic response of the pile bending moment under train vibration loads at DY1 mainly occurred in the early period of loading. The bending moment at DY2 increased with time from 0 to $2.4 \mathrm{~s}$. From $2.45 \mathrm{~s}$ to $3.0 \mathrm{~s}$, the bending moment at DY2 rapidly decreased and the value is about $30 \mathrm{kN} \cdot \mathrm{m}$ lower than the static calculation result (i.e., at $0 \mathrm{~s}$ ). After $3.0 \mathrm{~s}$, the bending moment at DY2 became stable. The dynamic response law of the bending moment at DY3 is similar to that at DY1.

Comparison between the three curves in Figure 11 shows that the dynamic response of the internal force of the support pile occurs between $0 \mathrm{~s}$ and $4 \mathrm{~s}$. After the dynamic response of support piles under the effect of train vibration loads, the residual internal forces are smaller than the calculated initial values of dynamics, respectively, $80 \mathrm{kN} \cdot \mathrm{m}, 22 \mathrm{kN} \cdot \mathrm{m}$, and $30 \mathrm{kN} \cdot \mathrm{m}$. Therefore, it can be approximated that the vibration response of the support pile structure of the foundation pit occurs under the effect of train vibration and the dynamic response process is in an elastic state. Compared to the research result by Yang and Cao [20], although the research result is supplied with a large numerical difference, it is all in an elastic state.

4.4. Dynamic Response of Prestressed Cables. Figure 12 is the axial force time history for four rows of prestressed anchor cables (refer to Figure 13 for the specific location) on pile M3 (refer to Figure 4 for the specific location) in the west of the foundation pit. As can be seen from the figure, the axial force of the first row of anchor cables remained stable from 0 to $1.3 \mathrm{~s}$ under the action of vibration loads. Starting from $1.3 \mathrm{~s}$, axial force dynamic response occurred in the first row of anchor cables as the load continued, with the maximum change of 


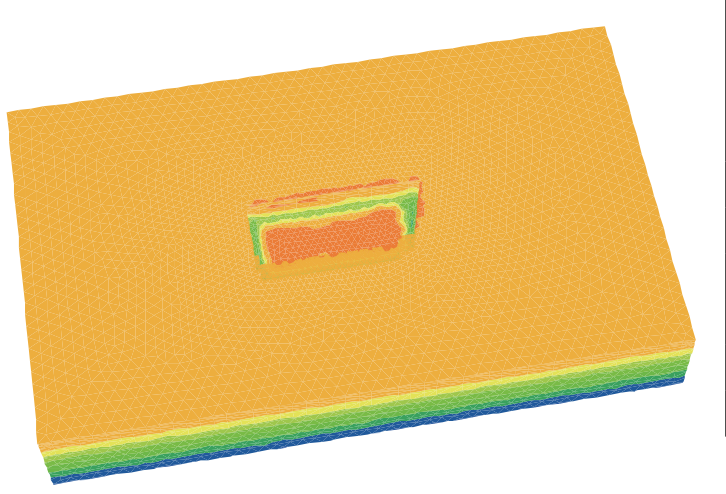

FIGURE 9: $X$ direction principal stress of the foundation pit.

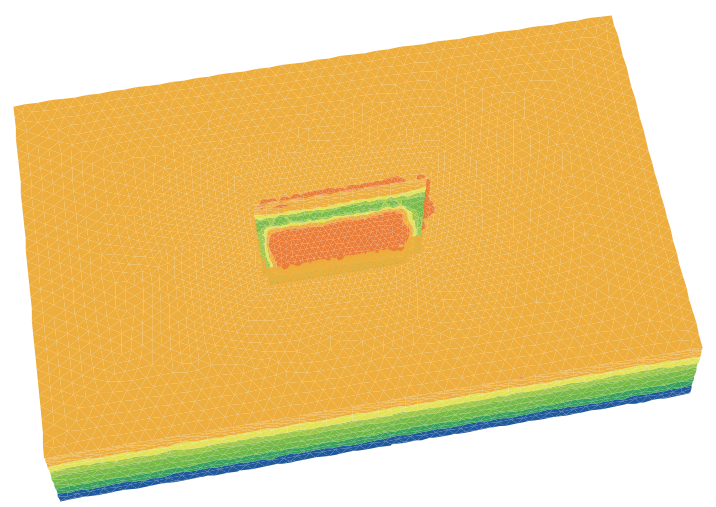

Contour of SYY

Magfac $=0.000 e+000$

Gradient calculation

$-7.2476 e+005$ to $-7.0000 e+005$

$-7.0000 e+005$ to $-6.0000 e+005$

$-6.0000 e+005$ to $-5.0000 e+005$

$-5.0000 e+005$ to $-4.0000 e+005$

$-4.0000 e+005$ to $-3.0000 e+005$

$-3.0000 e+005$ to $-2.0000 e+005$

$-2.0000 e+005$ to $-1.0000 e+005$

$-1.0000 e+005$ to $0.0000 e+000$

$0.0000 e+000$ to $1.0000 e+005$

$1.0000 e+005$ to $1.0067 e+005$

Interval $=1.0 e+005$

FIGURE 10: $Y$ direction principal stress of the foundation pit.

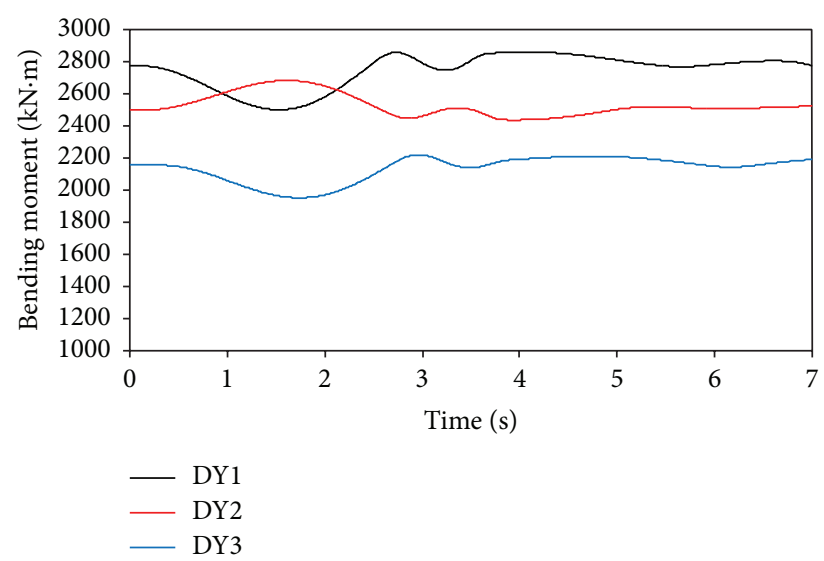

FIGURE 11: Time history curve of pile bending moment at the monitoring points monitoring site DY1 (black), monitoring site DY2 (red), and monitoring site DY3 (blue).

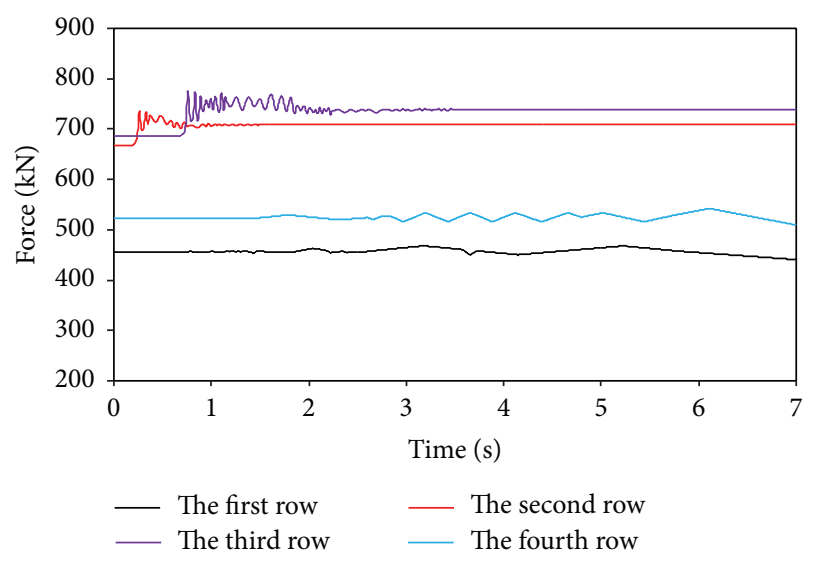

FIGURE 12: Anchor cable axial force time history. Monitoring site DM1 (black), monitoring site DM2 (red), monitoring site DM3 (purple), and monitoring site DM4 (blue). 


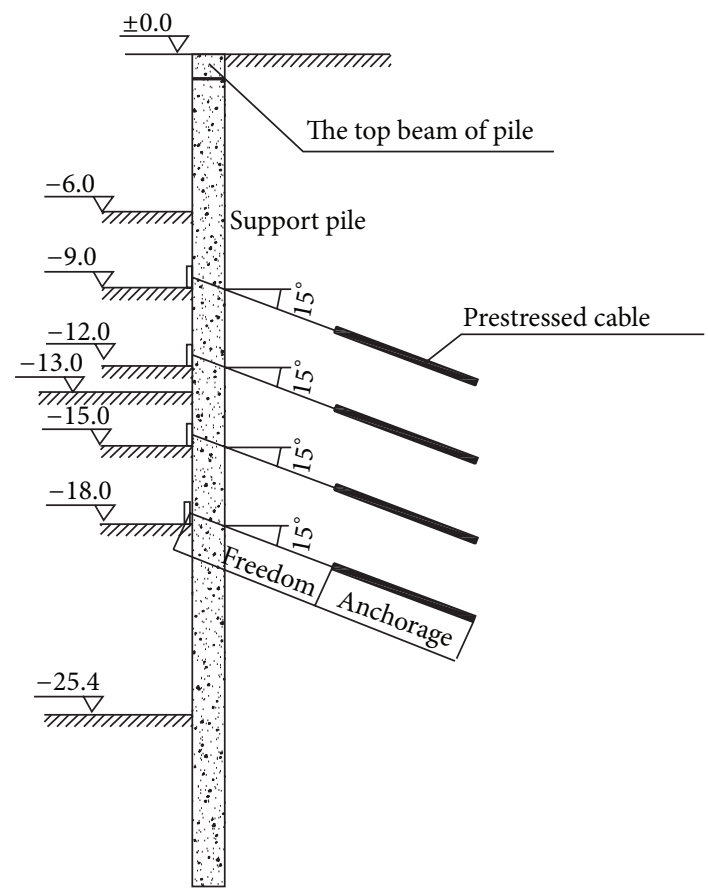

FigURE 13: Sectional view of foundation support structure.

$9.5 \mathrm{kN}$ and a range of $2.1 \%$. The axial force dynamic response of the second row occurred at $0.2 \mathrm{~s}$ and was obvious between $0.2 \mathrm{~s}$ and $1.0 \mathrm{~s}$, with the maximum change of $69.4 \mathrm{kN}$ and a range of $10.4 \%$. The axial force dynamic response of the third row occurred at $0.6 \mathrm{~s}$ and was obvious between $0.6 \mathrm{~s}$ and $2.0 \mathrm{~s}$. After $2.0 \mathrm{~s}$, the dynamic response began to weaken and the axial force became stable. The maximum change of the axial force of the third row was $84.8 \mathrm{kN}$, with a range of $12.3 \%$. The dynamic response law of the fourth row was similar to that of the first row.

Comparison between the four curves in Figure 12 shows that, under the action of train vibration loads, the axial force response of the first and fourth row of anchor cables is weak and that of the third row is the most obvious, followed by that of the second. The final axial forces of the first, second, third, and fourth rows of anchor cables increased by $14.0 \mathrm{kN}, 41.6 \mathrm{kN}, 52.1 \mathrm{kN}$, and $10.1 \mathrm{kN}$, respectively. Subway train vibration changes the initial internal force distribution of prestressed anchor cables and the force gathers inside the cables. Therefore, the action of train vibration loads is inimical to the safety of foundation pit support structures and should be closely studied.

\section{Conclusions}

Spectral analysis was conducted on rail acceleration oscillograms and the train vibration loads were derived. Taking the deep foundation pit of the New Chengdu Museum as an example, a dynamic three-dimensional numerical model was built that considers the vibration load of subway trains, and the following conclusions were drawn through calculation and analysis:
(1) Foundation pit soil subsidence: In the sandy cobble stratum media of Chengdu Plain where the site lies, the dynamic response of surface displacement mainly occurs in the early period of dynamic load. Train vibration is damped fast. The energy of surface displacement decays due to the damping of stratum soil in the later period of dynamic loading (1s-7s). The vibration load of subway trains has little impact on ground subsidence (the maximum subsidence is only $-2.26 \mathrm{~mm}$ ), no more than $0.15 H \%$ ( $H$ is the pit excavation depth) of the allowable surface subsidence for foundation pits. Surface vibration response becomes weaker and weaker with increasing distance from the source of train vibrations; the support piles provided can effectively reduce the surface vibration response caused by train vibrations.

(2) Foundation pit Earth pressure: The vibration of subway trains has significant impact on the Earth pressure behind the pile, and the closer the origin of vibration, the more intense the dynamic response.

(3) Dynamic response of support piles: The support piles' internal force dynamic response occurs between $0 \mathrm{~s}$ and $4 \mathrm{~s}$. After the dynamic response of the support piles under the effect of train vibration loads, the residual internal forces are smaller than the calculated initial values of dynamics, respectively, $80 \mathrm{kN} \cdot \mathrm{m}$, $22 \mathrm{kN} \cdot \mathrm{m}$, and $30 \mathrm{kN} \cdot \mathrm{m}$. Therefore, it can be approximated that the vibration response of the support pile structure of the foundation pit occurs under the effect of train vibration and the dynamic response process is in an elastic state.

(4) Dynamic response of prestressed cables: The axial force response of the first and fourth row of anchor cables is weak and that of the third row is the most obvious, followed by that of the second. Subway train vibration changes the initial internal force distribution of prestressed cables and the force gathers inside the cables. Therefore, the action of train vibration loads is inimical to the safety of foundation pit support structures and should be closely studied. The supporting structure of piles and anchor cables has to be adopted due to the foundation pit depth up to $25.4 \mathrm{~m}$; no negative influence of metro vibration on prestressed cable's power has been discovered in foreign and domestic reference literature, from which the unique feature of this study is induced.

\section{Conflict of Interests}

All the authors declare that there is no conflict of interests regarding the publication of this paper.

\section{Acknowledgments}

The authors gratefully acknowledge the project supported by the National Natural Science Foundation of China (Grant no. 41302256) and SWPU Geotechnical Mechanics and Engineering Science \& Technology Innovation (Cultivation) Youth Team (no. 2013XJZT006). 


\section{References}

[1] Z. B. Xiong, Z. F. Chen, and Z. Y. Duan, The Building Foundation Pit Supporting, China Building Industry Press, Beijing, China, 2007.

[2] X. H. Zhao and B. Li, Engineering Practice and Theory on Large Deep Foundation Pit, China Communications Press, Beijing, China, 2004.

[3] China Academy of Building Research, "Construction of foundation pit supporting technology procedures," Tech. Rep. JGJ120-99, China Building Industry Press, Beijing, China, 1999.

[4] L. S. Yang, Research on variation characteristics of stress and displacement fields surrounding foundation pit induced by excavation [Ph.D. thesis], Tongji University, Shanghai, China, 2007.

[5] Y. M. Yao, Research on the deep foundation pit of urban rail transit parallel transfer station deformation and control [Ph.D. thesis], Institute of Transportation, Tongji University, Shanghai, China, 2003.

[6] Q. Zong, H. B. Wang, and S. B. Zhou, "Research on monitoring and controlling techniques considering effects of seismic shock," Chinese Journal of Rock Mechanics and Engineering, vol. 27, no. 5, pp. 938-945, 2008.

[7] V. Corinaldesi and G. Moriconi, "Behavior of beam-column joints made of sustainable concrete under cyclic loading," Journal of Materials in Civil Engineering, vol. 18, no. 5, pp. 650658, 2006.

[8] D. R. Morgan, K. Kazakoff, and H. Ibrahim, "Seismic retrofit of a concrete immersed tube tunnel with reinforced shotcrete," in Proceedings of the 10th International Conference on shotcrete for Underground Support, ASCE, Whistler, Canada, September 2006.

[9] L. Hall, "Simulations and analyses of train-induced ground vibrations in finite element models," Soil Dynamics and Earthquake Engineering, vol. 23, no. 5, pp. 403-413, 2003.

[10] X. L. Bi and S. H. Zhou, "Analysis on deformation of old metro station close to deep excavation by vehicle dynamic loads," Journal of Tongji University, vol. 32, no. 12, pp. 1599-1602, 2004.

[11] L. Y. Ma, Y. Ding, C. C. Guo, and Q. Guan, "Based on FLAC3D analysis of foundation pit structure response under moving loads," Engineering and Construction, vol. 25, no. 1, pp. 90-93, 2011.

[12] L. Andersen and C. J. C. Jones, "Coupled boundary and finite element analysis of vibration from railway tunnels-a comparison of two- and three-dimensional models," Journal of Sound and Vibration, vol. 293, no. 3-5, pp. 611-625, 2006.

[13] Z. Z. Hu and W. B. Jian, "Analysis and test on applicability of geotechnical engineering anchorage in permanent vibration environment," Rock and Soil Mechanics, vol. 31, no. 8, pp. 25992603, 2010.

[14] A. Bagherzadeh, B. Ferdosi, J. Nakhaei, and M. J. Nasri, "Numerical analysis of the support system in the transition zone of the Esfahan subway project," Arabian Journal of Geosciences, vol. 8, no. 6, pp. 3985-4000, 2015.

[15] E. J. Cording, J. H. Long, M. Son, and D. F. Laefer, "Modeling and analysis of excavation-induced building distortion and damage using a strain-based damage criterion," in Proceedings of the International Conference Response of Buildings to Excavation-Induced Ground Movements, CIRIA, London, UK, 2011.

[16] Y. Q. Tang, C. Q. Luan, X. Zhang, J. X. Wang, and P. Yang, "Numerical simulation of saturated soft clay's deformation around tunnel under subway vibrational loading," Underground Space and Engineering, vol. 14, no. 4, pp. 105-110, 2008.

[17] C. Lin, Y. F. Luo, S. P. Wang, and G. H. Cai, "Monitoring and effect of moving load to foundation excavation support configuring," Journal of Highway and Transportation Research and Development, vol. 29, no. 11, pp. 110-114, 2008.

[18] C. X. Shi, Q. Yang, and Z. Y. Guo, "Mechanical analysis on cement concrete pavement in highway tunnel under moving load," Highway and Transportation Research and Development, vol. 25, no. 10, pp. 23-25, 2008.

[19] J. Huang, L. Peng, and C. Chen, "Dynamic responses of railway tunnels under high-speed moving loads," Journal of Zhengzhou University (Engineering Science), vol. 29, no. 3, pp. 117-121, 2008.

[20] L. Yang and S. Cao, "Research on the deformation law of foundation pit under the train dynamic load," Journal of Anhui Jianzhu University, vol. 22, no. 4, pp. 49-53, 2014. 

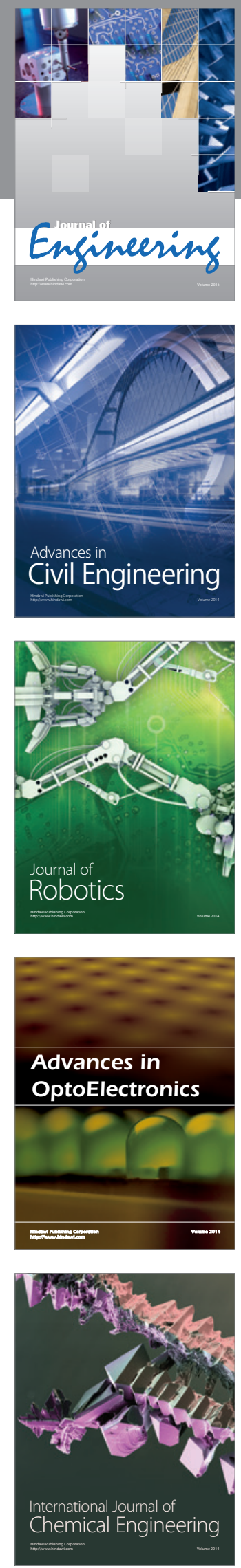

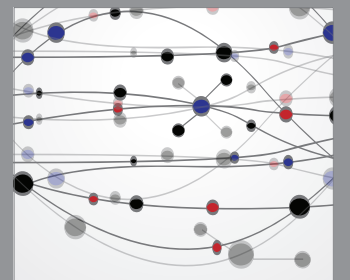

The Scientific World Journal
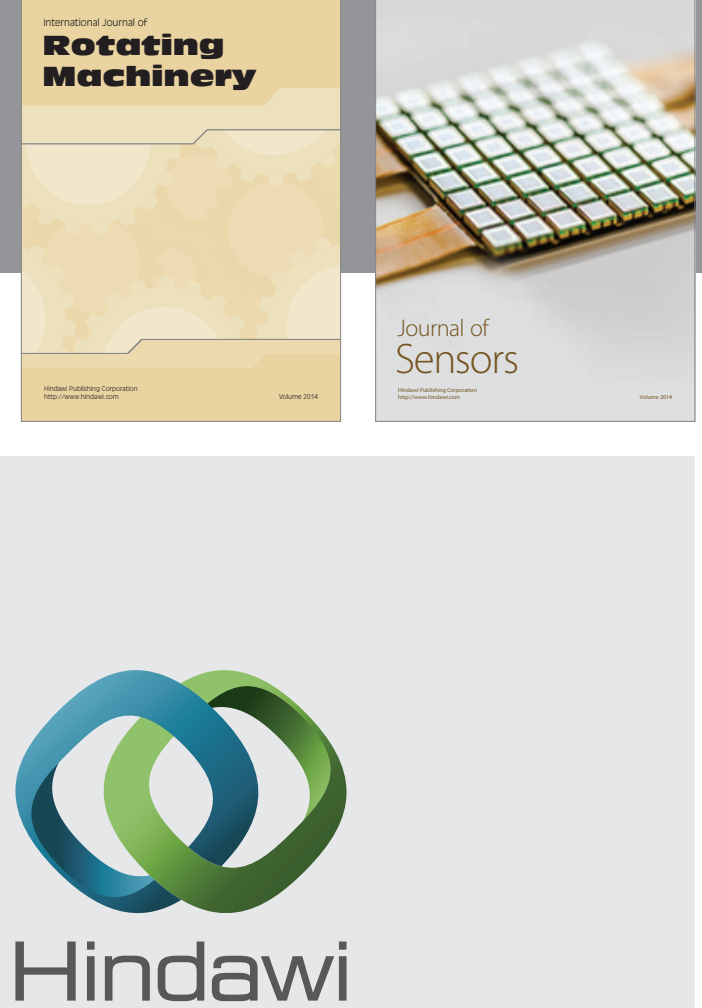

Submit your manuscripts at http://www.hindawi.com
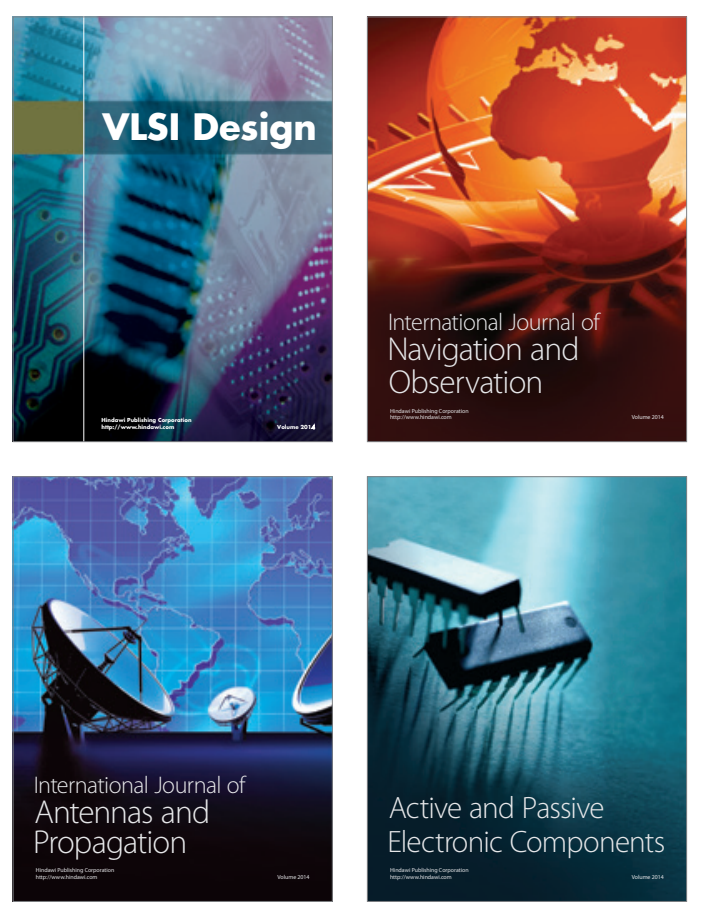
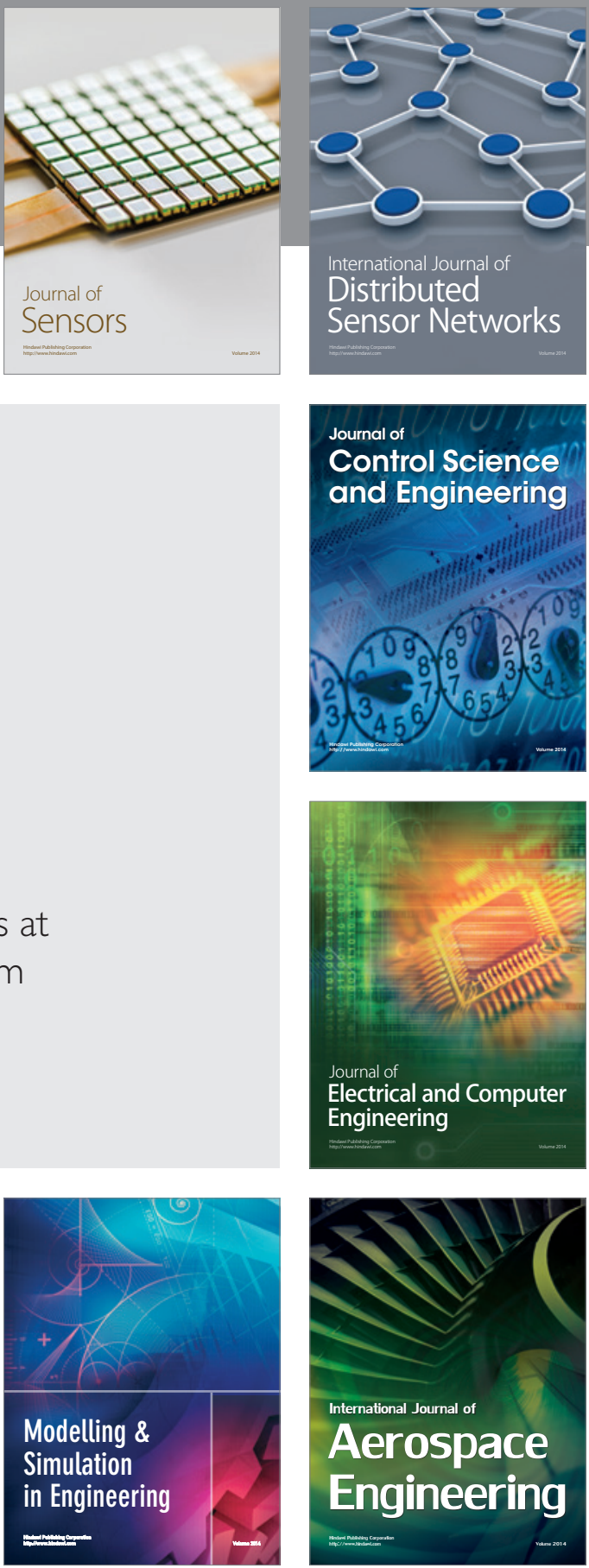

Journal of

Control Science

and Engineering
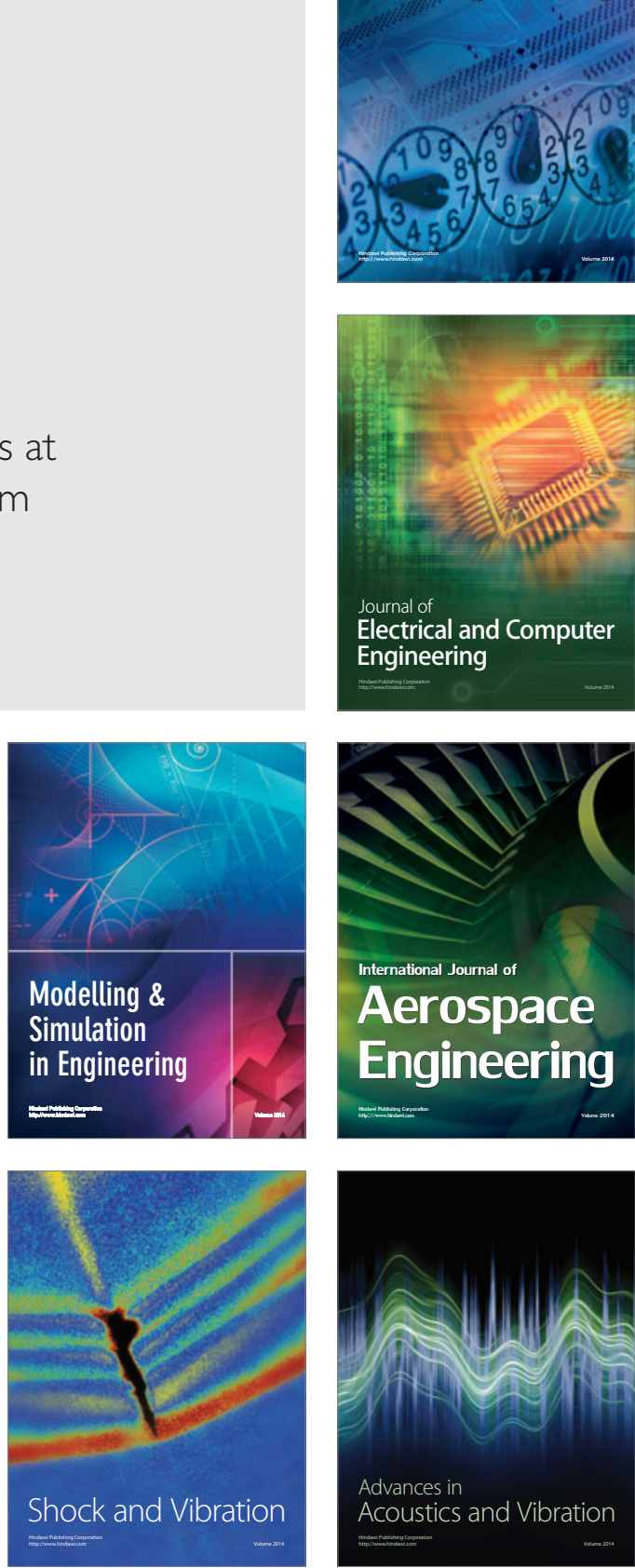